\title{
Caracterizações morfológica e agronômica e divergência genética em germoplasma de trevo-branco ${ }^{1}$
}

\author{
Fernanda Bortolini' ${ }^{2}$, Miguel Dall'Agnol ${ }^{3}$, Maria Teresa Schifino-Wittmann ${ }^{3}$, Miriam Trevisan ${ }^{4}$, \\ Vladirene Macedo Vieira ${ }^{4}$, Simone Meredith Scheffer-Basso ${ }^{5}$, Daniel Portela Montardo ${ }^{6}$ \\ ${ }^{1}$ Parte da dissertação apresentada pela primeira autora ao Programa de Pós-Graduação em Zootecnia, Departamento de Plantas Forrageiras \\ e Agrometeorologia, Faculdade de Agronomia, UFRGS, financiada pelo CNPq. \\ 2 Doutoranda do PPG - Zootecnia, Depart. de Plantas Forrageiras e Agrometeorologia da Fac. de Agron. da UFRGS. Bolsista do CNPq. \\ ${ }^{3}$ Departamento de Plantas Forrageiras e Agrometeorologia - UFRGS. Caixa Postal 15100, CEP: 91501-970, Porto Alegre, RS. \\ ${ }^{4}$ Curso de Graduação em Agronomia da UFRGS, Bolsistas PIBIC/UFRGS e CNPq, respectivamente. \\ 5 ICB e FAMV da Universidade de Passo Fundo (UPF), RS. \\ ${ }^{6}$ FEPAGRO, ljuí, RS.
}

RESUMO - Objetivou-se caracterizar a variabilidade existente e estimar a divergência genética de uma coleção nuclear de trevo-branco formada por 78 acessos. Dezessete plantas de cada acesso foram caracterizadas com base em nove parâmetros (oito morfológicos e um agronômico): estatura das plantas, hábito de crescimento, intensidade de florescimento, comprimento de estolão, número de nós por estolão, comprimento dos entrenós, diâmetro de estolão, produção total de MS e área foliar por planta. Pela estimativa da distância de Mahalanobis, os acessos 1 (PI 195534) e 10 (PI 419325) apresentaram a maior distância $(45,4)$ e os acessos 58 (PI 180491) e 68 (PI 197830), a menor distância (0,19). A área foliar foi a característica com maior contribuição relativa para divergência genética (24\%), seguida pela estatura da planta (20\%), pela intensidade de florescimento $(19 \%)$ e pela produção total de MS (15\%). A análise de correlação linear simples entre as variáveis mostrou correlação positiva e significativa entre estatura e área foliar $(0,92)$, assim como entre comprimento de estolão e comprimento de entrenós $(0,90)$.

Palavras-chave: forrageira hibernal, melhoramento vegetal, morfologia, variabilidade genética

\section{Agronomic and morphological characterizations and genetic divergence on white clover germplasm}

\begin{abstract}
This work aimed to evaluate morphological features of the white clover core collection obtained from the United States Department of Agriculture (USDA), represented by 78 accessions, in order to characterize the existent morphological variability and to estimate the genetic divergence, using nine characters (eight morphological and one agronomic). Seventeen plants from each access were evaluated individually at the Experimental Station of the Universidade Federal do Rio Grande do Sul in Eldorado do Sul and characterized in relation to the following characters: plant height, growth habit, flowering intensity, stolon length, node number per stolon, internode length, stolon diameter, total dry matter yield and leaf area per plant. Using the estimate of Mahalanobis' distance, the results showed that the accessions 1 (PI 195534) and 10 (PI 419325) presented the greatest distance (45.4), while the accessions 58 (PI 180491) and 68 (PI 197830) presented the smallest distance (0.19). The leaf area was the character with the largest individual relative contribution to the genetic divergence $(24 \%)$, followed by plant height $(20 \%)$, flowering intensity $(19 \%)$ and total dry matter yield $(15 \%)$. There was a positive and highly significant correlation between plant height and leaf area (0.92) and also between stolon length and internode length (0.90).
\end{abstract}

Key Words: morphology, plant breeding, variability, winter forage

\section{Introdução}

O trevo-branco (Trifolium repens L.) é uma das leguminosas forrageiras mais importantes e amplamente distribuída no mundo (Zohary \& Heller, 1984), adaptada principalmente em zonas temperadas (Mather et al., 1995). No Rio Grande do Sul, possui papel fundamental nas pasta- gens, destacando-se tanto pela alta produtividade como pela qualidade da forragem (Nabinger, 1980), sendo uma das espécies de leguminosas mais utilizadas em pastagens consorciadas durante o inverno e a primavera (Paim \& Riboldi, 1994). Sua ampla distribuição, ligada à sua natureza alógama, tem originado ampla variação adaptativa, principalmente em resposta a fatores climáticos (García, 1995). 
O trevo-branco possui duração perene, porém, dependendo das interações, favoráveis ou desfavoráveis, e dos fatores climáticos sobre seu desenvolvimento, pode ser anual, de ressemeadura natural ou bienal (Gibson \& Hollowell, 1966). Os principais fatores envolvidos na baixa persistência dessa leguminosa são de origem climática (Arana et al., 2000) e, no Rio Grande do Sul, destacam-se as altas temperaturas do verão e a baixa disponibilidade de água nesse período (Paim, 1988). Nas condições climáticas do estado, a sobrevivência do estolão e a ressemeadura natural são fatores que asseguram a persistência da espécie nas pastagens (Paim, 1993).

A seleção natural, auxiliada pelos melhoristas, tem possibilitado a separação de genótipos da espécie com diferentes tamanhos de folhas, ampliando a utilidade do trevo-branco (Mather et al., 1995). O tamanho de folha tem sido a principal característica de diferenciação entre cultivares dessa espécie, sendo reconhecidos três grupos: folhas pequena, média e grande (García, 2000).

No desenvolvimento do trevo-branco, após o estádio inicial de plântula, os estolões emergem da axila das folhas formando uma rede de estolões ramificados. Durante essa fase, o trevo-branco tem ampla capacidade de propagação e seu comportamento é condicionado pelo microambiente em volta dos estolões (Frame et al., 1997). A importância do estolão está relacionada à persistência da planta, visto que a permanência do trevo na pastagem resulta da produção continuada de estolões ou de sementes. Além disso, o comprimento do estolão está relacionado aos diferentes tipos morfológicos, de modo que as plantas com estolões mais longos geralmente apresentam folhas e flores pequenas, hábito prostrado, ciclo curto e baixa produtividade (Carámbula, s.d.). Como o estolão é a unidade básica de crescimento do trevo-branco, sua morfologia deve ser considerada em programas de melhoramento (Thomas, 1980).

A variabilidade das características morfológicas de trevo-branco tem sido avaliada por vários autores visando estudar suas relações com a persistência das plantas. Alguns pesquisadores (Viecelli, 2000; Helgadóttir, 2001; Lüscher et al., 2001) realizaram a caracterização de tipos morfológicos distintos e verificaram relação entre as diferentes características (comprimento de estolão, diâmetro de estolão, comprimento de pecíolo, entre outras). Outros documentaram os efeitos de estresses bióticos e abióticos e das diferentes condições de luz e temperatura sobre a morfologia e a plasticidade da espécie (Beinhart, 1963; Sanderson et al., 2003; Seker et al., 2003, entre outros).

Identificando pesquisas que melhorem a eficiência das estratégias de melhoramento para trevo-branco na Austrália, Jahufer et al. (2002) ressaltaram o papel do uso do germoplasma no melhoramento e a importância de se caracterizar a diversidade genética dentro e entre acessos para atributos importantes. Neste trabalho, objetivou-se estimar a divergência genética de uma coleção nuclear de trevo-branco por meio de marcadores morfológicos e agronômicos, a fim de aumentar a eficiência no melhoramento da espécie.

\section{Material e Métodos}

Foram utilizados 78 acessos que compõem a coleção nuclear de trevo-branco proveniente do Sistema Nacional de Germoplasma Vegetal(NPGS - National Plant Germoplasm System) do Departamento de Agricultura dos Estados Unidos (USDA - United States Department of Agriculture). Desses 78, dois acessos (36 e 52) apresentaram problemas de germinação e persistência no campo e, por isso, não foram analisados. A numeração e a respectiva identificação dos acessos encontram-se na Tabela 1.

O experimento foi realizado na casa de vegetação, em Porto Alegre, e no campo, na Estação Experimental Agronômica (EEA) da Faculdade de Agronomia da Universidade Federal do Rio Grande do Sul. A EEA está situada em Eldorado do Sul, RS, na região fisiográfica da Depressão Central, a $30^{\circ} 06^{\prime}$ de latitude sul, $51^{\circ} 39^{\prime}$ de longitude oeste e altitude média de $46 \mathrm{~m}$. O clima da região pertence à variedade específica $\mathrm{Cfa}$ - subtropical úmido, com verão quente, conforme classificação climática de Köppen. O solo da área experimental pertence à unidade de mapeamento "São Jerônimo", sendo classificado como Argissolo Vermelho distrófico típico-Pvd(Streck et al., 2002) e foi corrigido com $160 \mathrm{~kg} / \mathrm{ha}$ de $\mathrm{P}_{2} \mathrm{O}_{5}$ sob a forma de superfosfato simples e $60 \mathrm{~kg} / \mathrm{ha}$ de $\mathrm{K}_{2} \mathrm{O}$ sob a forma de cloreto de potássio, segundo recomendações da análise de solo.

A partir de maio de 2002, em casa de vegetação, foram semeadas 25 sementes de cada acesso em bandejas de isopor contendo substrato comercial utilizado para mudas. Após germinação, quando já estavam desenvolvidas, as plântulas foram transferidas para copos plásticos, permanecendo uma em cada copo. Nos dias 14 e 15 de maio de 2003, foi realizado o transplante de 17 plantas de cada um dos acessos de trevo-branco para o campo (EEA). As plantas foram espaçadas 1,25 m uma das outras, sendo cada uma considerada uma unidade experimental, em um delineamento completamente casualizado, com 17 repetições. No dia 06 de junho, foram substituídas as plantas que haviam morrido até essa data. No dia 08 de agosto, realizou-se aplicação de solução com inoculante (Rhizobium leguminosarum bv. trifolii, estirpe SEMIA 222) na dosagem de de $17 \mathrm{~mL} /$ planta. Todos os descritores morfológicos utilizados nesse trabalho foram sugeridos pelo International 
Tabela 1 - Identificação dos acessos da coleção nuclear de trevo-branco Table 1 - Access identification of white clover core collection

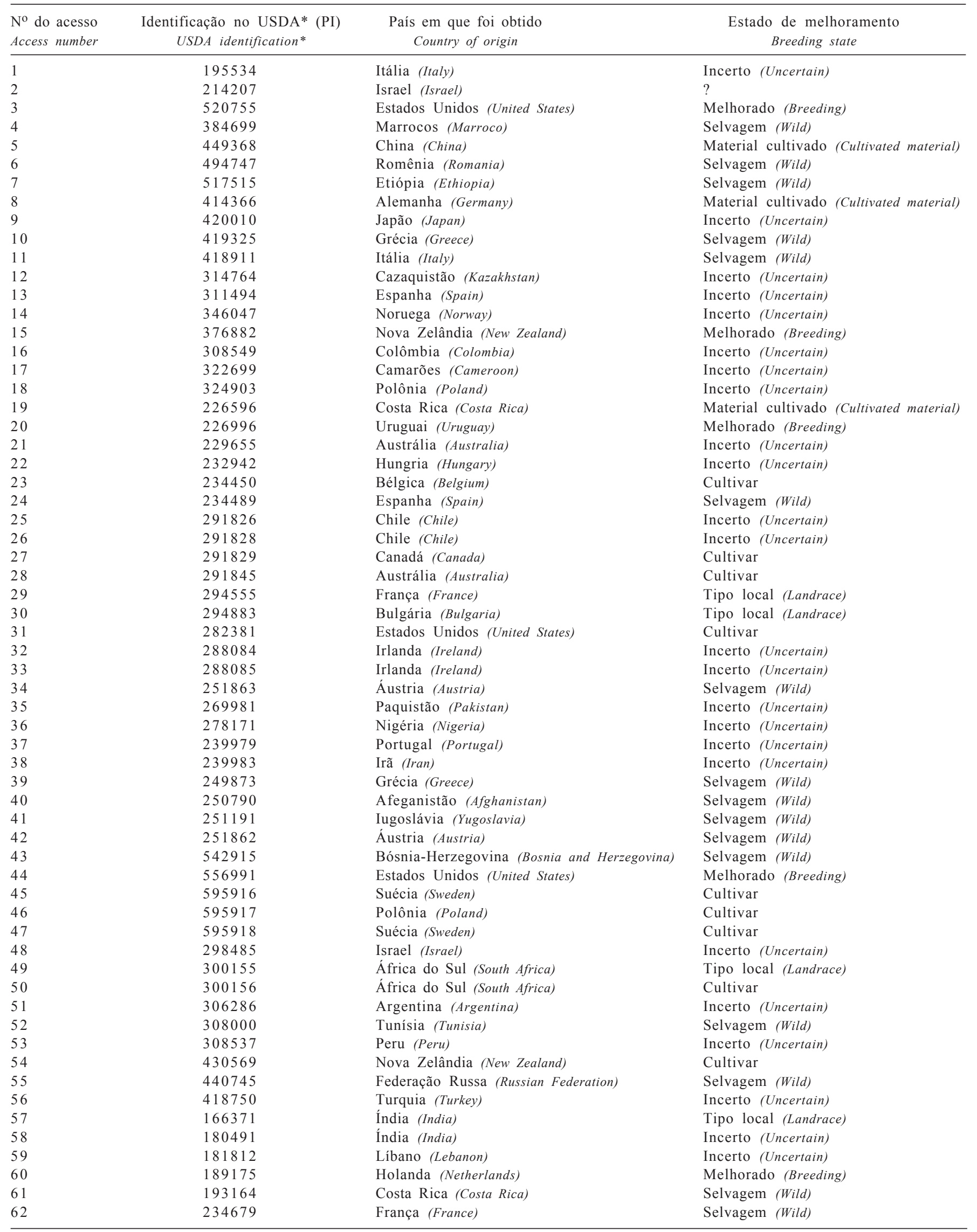




\begin{tabular}{|c|c|c|c|}
\hline $\begin{array}{l}\mathrm{N}^{\mathrm{O}} \text { do acesso } \\
\text { Access number }\end{array}$ & $\begin{array}{c}\text { Identificação no USDA* (PI) } \\
\text { USDA identification* }\end{array}$ & $\begin{array}{l}\text { País em que foi obtido } \\
\text { Country of origin }\end{array}$ & $\begin{array}{c}\text { Estado de melhoramento } \\
\text { Breeding state }\end{array}$ \\
\hline 63 & 234828 & Suíça (Switzerland) & Selvagem (Wild) \\
\hline 64 & 234937 & Suíça (Switzerland) & Selvagem (Wild) \\
\hline 65 & 237292 & Dinamarca (Denmark) & Cultivar \\
\hline 66 & 237733 & Alemanha (Germany) & Cultivar \\
\hline 67 & 239977 & Portugal (Portugal) & Incerto (Uncertain) \\
\hline 68 & 197830 & Jamaica (Jamaica) & Incerto (Uncertain) \\
\hline 69 & 197871 & Argentina (Argentina) & Incerto (Uncertain) \\
\hline 70 & 205062 & Turquia (Turkey) & Incerto (Uncertain) \\
\hline 71 & 222210 & Afeganistão (Afghanistan) & Material cultivado (Cultivated material) \\
\hline 72 & 226102 & Quênia (Kenya) & Cultivar \\
\hline 73 & 384020 & Polônia (Poland) & Cultivar \\
\hline 74 & 404543 & Brasil (Brazil) & Material cultivado (Cultivated material) \\
\hline 75 & 404930 & Uruguai (Uruguay) & Material cultivado (Cultivated material) \\
\hline 76 & 499688 & China (China) & Selvagem (Wild) \\
\hline 77 & 516411 & Romênia (Romania) & Incerto (Uncertain) \\
\hline 78 & 517126 & Marrocos (Morocco) & Selvagem (Wild) \\
\hline
\end{tabular}

$?=$ não se tem informação.

* USDA = Departamento de Agricultura dos Estados Unidos.

?=Information not available.

*USDA = United States Department of Agriculture.

Board for Plant Genetic Resources (IBPGR, 1992). As avaliações foram realizadas quando a maioria dos acessos já se apresentavam florescidos.

Foram realizadas as seguintes avaliações: determinação da área foliar por planta (AF), sendo coletadas quatro folhas (12 folíolos) por planta e colocadas em caixas de isopor contendo gelo, para conservação até a chegada ao Laboratório de Ecofisiologia Vegetal, onde foi realizada a medição da área foliar total, em $\mathrm{cm}^{2}$, de 12 folíolos por indivíduo em um planímetro ótico modelo LICOR 3100. Posteriormente, foi calculada a média dos folíolos medidos, a fím de se obter a área foliar por folha. Os valores extremos de AF foram verificados para os acessos 1 (maiores) e 10 (menores). Por isso, atribuíram-se intervalos de AF a fim de classificar os acessos em três grupos em relação ao tamanho de folha. Os acessos que apresentaram AF acima de $11 \mathrm{~cm}^{2}$ foram considerados de folhas grandes, os de folhas pequenas foram aqueles com folíolos de no máximo $4,09 \mathrm{~cm}^{2}$ e o restante foi considerado de folhas intermediárias. Em geral, o trevo-branco é classificado nestes três grupos conforme o tamanho das folhas (Carámbula, s.d.). No entanto, não há referência na literatura sobre quais seriam os limites para cada um desses diferentes grupos. Para determinação do comprimento de estolão (CES), foi medido um estolão por planta com o auxílio de uma régua graduada em centímetros, a qual era colocada na base da planta, sendo medida a distância até o ápice. Em seguida, efetuou-se a contagem do número de nós por estolão (NN) e, utilizando-se os valores de comprimento do estolão e seu número de nós, calculou-se o comprimento médio dos entrenós (CEN), em centímetros. A estatura das plantas
(ES) foi medida com auxílio de uma régua graduada em centímetros; o hábito de crescimento (HAB) foi avaliado visualmente, sendo atribuídas notas 1, 2 e 3 para plantas prostradas, decumbentes e eretas, respectivamente; para a intensidade de florescimento (IF), foram atribuídas notas de 0 a 3 , em que: $0=$ plantas sem nenhuma inflorescência ou botão floral; 1 = plantas com uma ou poucas inflorescências; 2 = plantas com número médio de inflorescências; e $3=$ plantas com florescimento abundante. O diâmetro de estolão (DE) foi medido utilizando-se um paquímetro, o qual era colocado no primeiro entrenó, imediatamente após o primeiro nó. A avaliação da produção de MS foi realizada com base em dois cortes, o primeiro nos dias 15 e 16 de setembro e o segundo nos dias 24, 26 e 27 de outubro. As plantas foram cortadas a $3 \mathrm{~cm}$ do solo e o material foi colocado individualmente em sacos de papel e em estufas a $60^{\circ} \mathrm{C}$ até peso constante.

Primeiramente, as variáveis avaliadas, com dez repetições por acesso, foram submetidas à análise estatística pelo Programa Genes (Cruz, 2001), no qual os dados foram analisados pelo procedimento de análise multivariada com o objetivo de serem obtidas informações sobre a importância relativa dos caracteres avaliados e o grau de dissimilaridade genética entre os acessos na coleção. Para isso, foi gerada uma matriz de dissimilaridade por meio da distância de Mahalanobis, que automaticamente padroniza os dados para estimar a variância, uma vez que foram oriundos de delineamento experimental com repetições. Com esse procedimento, também foi gerada a importância relativa dos caracteres, segundo método de Singh. Posteriormente, foi 
realizado o agrupamento dos acessos com similaridade de padrão de comportamento, por meio do método de Tocher, que adota o critério de que a média das medidas de dissimilaridade dentro de cada grupo deve ser menor que as distâncias entre quaisquer grupos. Por último, foi realizada a análise de correlação linear simples (Pearson) entre as variáveis utilizando-se os valores médios (média de dez acessos) para cada uma das sete variáveis avaliadas, por meio do pacote estatístico SANEST (Alves et al., 1993). As variáveis hábito de crescimento e intensidade de florescimento (qualitativas) não foram consideradas na análise de correlação.

\section{Resultados e Discussão}

Os valores de média e desvio-padrão para os caracteres morfológicos encontram-se na Tabela 2. Obteve-se uma amplitude considerável $\left(1,85\right.$ a 13,16 $\left.\mathrm{cm}^{2}\right)$, para área foliar, ou tamanho médio dos folíolos, o que permitiu classificar os acessos em três grupos conforme o tamanho de folha. Assim, os acessos 1, 3, 4, 9, 18, 49, 50 e 74 foram os que apresentaram maior área foliar (acima de $11 \mathrm{~cm}^{2}$ de AF), pertencendo ao grupo "folhas grandes"; o grupo "folhas pequenas" (com AF de no máximo $4,09 \mathrm{~cm}^{2}$ ) incluiu os acessos 4, 6, 10, 32, 34, 35, 39, 41, 60, 61 e 71; os acessos restantes foram enquadrados no tipo "folhas intermediárias", com AF de 4,09a $11 \mathrm{~cm}^{2}$. Verificou-se, então, que as plantas de folhas pequenas apresentaram hábito prostrado, ao passo que as de folhas grandes mostraram-se eretas, conforme descrito por García (1995) e Carámbula (s.d.).

Com base na média dos genótipos, os acessos 67 e 2 apresentaram maior comprimento de estolão $(33,0 \pm 10,7$ e $32,1 \pm 11,1 \mathrm{~cm}$, respectivamente), de modo que o acesso 2 se destacou ainda por apresentar maior comprimento de entrenós $(2,28 \pm 0,53)$, assim como maior produção de MS. Ao contrário, os acessos 12 e 44 foram aqueles com menor comprimento de estolão $(11,4 \pm 5,3$ e 12,1 $\pm 5,8 \mathrm{~cm}$, respectivamente).

O maior número de nós por estolão $(\mathrm{NN})$ foi observado nos acessos 57 (21 nós) e 78 (22 nós), os quais apresentaram hábito prostrado. Por sua vez, o menor NN (13 nós) foi verificado nos acessos 17 e 38, prostrados. Quanto ao florescimento, os acessos com maior intensidade de florescimento, em média, foram aqueles classificados, neste trabalho, como intermediários quanto ao tamanho de folha (acessos 7, 17, 19, 20, 28, 53, 75 e 78), à exceção do acesso 4, de folhas pequenas. Esses resultados corroboram os relatos de Mather et al. (1995), que afirmaram que os tipos de folha intermediários apresentam florescimento mais abundante que os do tipo grande. Em contrapartida, a maioria dos acessos não florescidos pertence a esse mesmo grupo (folhas intermediárias), poucos ao grupo "folhas pequenas" $(32,34$ e 60$)$ e apenas o acesso 9 ao grupo "folhas grandes".

$\mathrm{O}$ acesso 31 foi o que apresentou, em média, maior diâmetro de estolão $(5,62 \pm 0,49 \mathrm{~mm})$, superior ao dobro do encontrado para a maioria dos outros acessos. O acesso 39, no entanto, foi aquele com menor diâmetro de estolão $(1,56 \pm 0,34 \mathrm{~mm})$.

Considerando os dados médios de produção de MS, o acesso 2 foi o que apresentou maior produção total, assim como no $1^{\circ}$ e $2^{\circ}$ cortes $(69,8 ; 13,2$ e $56,6 \mathrm{~g} /$ planta, respectivamente), seguido dos acessos 75, 20 e 78, 7, 48, 33, 59, 3 e 67, com produção total de MS superior a $30 \mathrm{~g} /$ planta. Pela análise desses dados, verifica-se que esses resultados confirmam os relatos de Viecelli (2000) de que plantas que começam a produzir forragem antes apresentam maiores produções totais de MS. Os acessos 34 e 35 foram os que apresentaram menor produção de MS no $1^{\circ}$ e $2^{\circ}$ cortes, assim com menor produção de MS total, seguido dos acessos 12, 10, 71, 76, 41 e 44, com menos de $10 \mathrm{~g} /$ planta.

O resumo das estimativas das distâncias genéticas, com base na distância de Mahalanobis, encontra-se na Tabela 3. O valor máximo de divergência verificado foi de 45,4 entre os acessos 1 e 10. O acesso 1 (PI 195534) apresentou-se ereto, com grande área foliar, estolões longos e grossos e florescimento médio. $\mathrm{O}$ acesso 10 (PI 419325), no entanto, mostrou-se prostrado, com área foliar muito pequena, estolões longos e delgados, pouco florescido, com mesmo número de nós por estolão e metade da produção total de MS do acesso 1. A menor divergência foi de 0,19 entre dois materiais com estado incerto de melhoramento, acessos 58 (PI 180491) e 68 (PI 197830), ambos com valores muito semelhantes para todas as características avaliadas, sendo plantas prostradas, com estolões longos, baixa área foliar, boa produção de MS e florescimento médio.

A análise de agrupamento evidenciou a formação de 12 grupos (Tabelas 2 e 4). Houve a formação de grupos com características marcantes em termos de número de componentes. Por exemplo, houve a formação de três grupos com apenas um acesso e outros três formados por dois acessos. Por outro lado, dois dos outros grupos restantes concentraram a maioria dos acessos (41 acessos), evidenciando a diversidade entre os grupos, explicada, em parte, pelo fato de que a diversidade genética não está correlacionada à diversidade geográfica, fato confirmado pela existência de acessos de origens geográficas diferentes, classificados no mesmo grupo de divergência genética, e acessos de mesma origem geográfica classificados em grupos diferentes. 
Tabela 2 - Média (M) e desvio-padrão (S) para comprimento de estolão (CES), número de nós por estolão (NN), diâmetro de estolão (DE), comprimento de entrenó (CEN), área foliar por folha (AF), estatura (ES) e produção de MS por planta (MS/planta) e máximo (Ma) e mínimo (Mi) para hábito de crescimento (HA) e intensidade de florescimento (IF) dos acessos de trevo-branco

Table 2 - Average (M) and standard deviation (s) for white clover accessions for the characters stolon length (CES), number of nodes per stolon (NN), stolon diameter (DE), internode length (CEN), leaf area per leaf ( $A F)$, plant height (ES) and dry matter yield per plant (MS/planta) and maximum (Ma) and minimum (Mi) for growth habit (HA) and flowering intensity (IF)

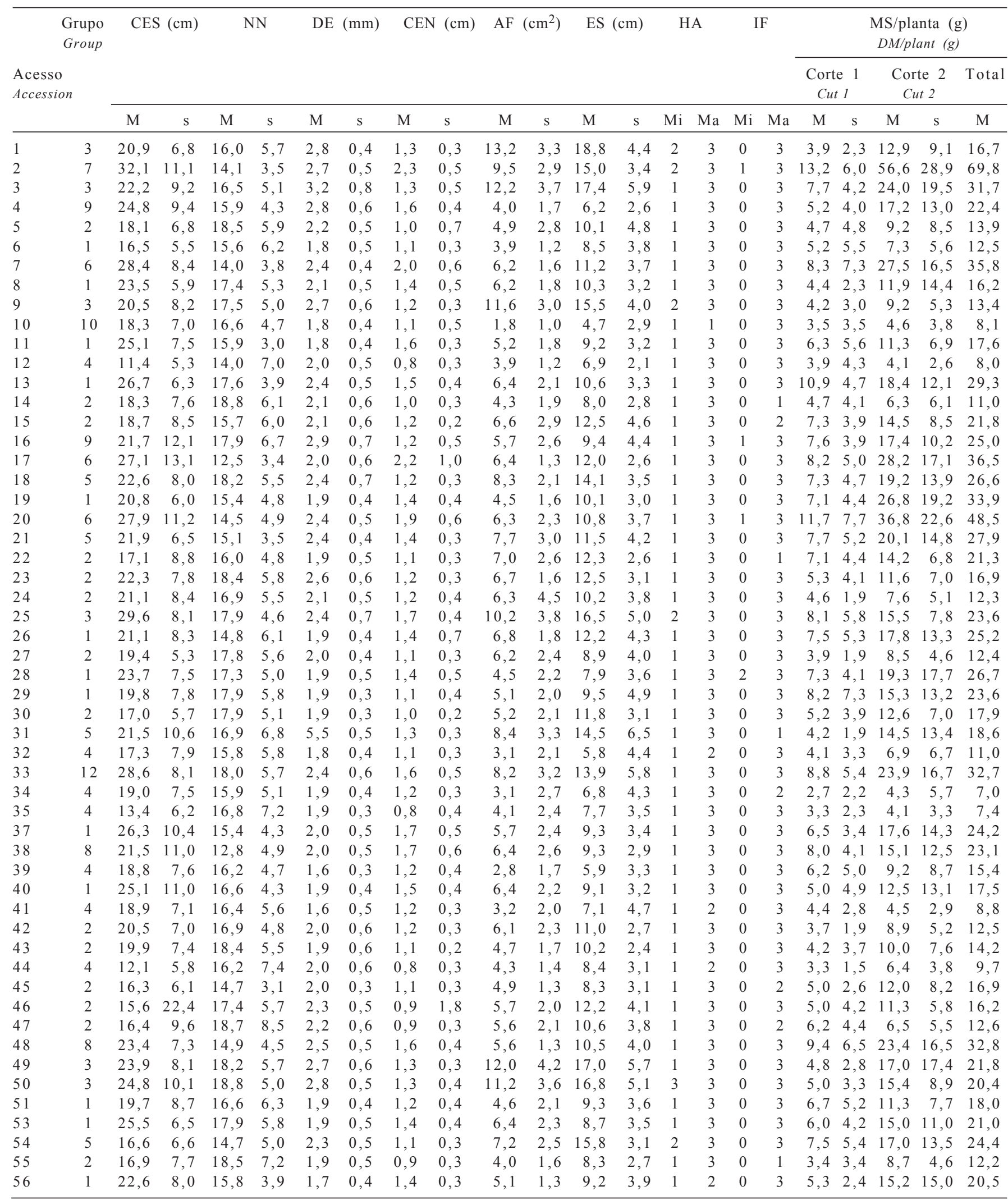


Continuação da Tabela 2 ...

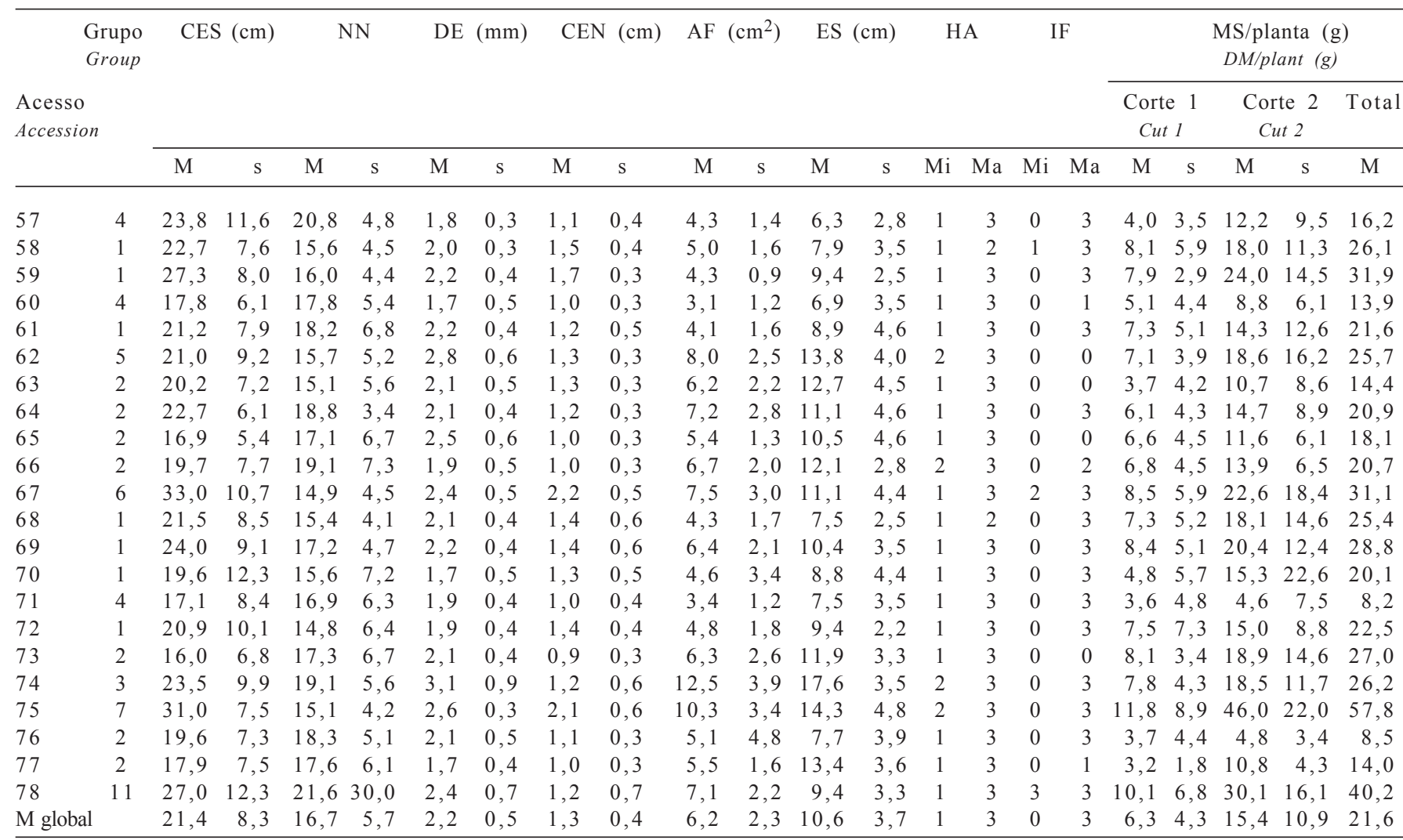

Grupos = grupos de acessos estabelecidos pelo método de Tocher, com base na dissimilaridade genética expressa pela distância de Mahalanobis (12 grupos formados); $\mathrm{HA}=$ hábito de crescimento ( 1 = prostrado, 2 = decumbente, 3 = ereto $)$; IF = intensidade de florescimento $(0=$ não florescido, 1 = pouco florescido, 2 = florescimento médio, 3 = florescimento intenso)

Groups = accessions groups formed by the Tocher method, based on the genetic dissimilarity expressed by the Mahalanobis distance (12 groups formed); HA = growth habit ( 1 = prostrate; 2 = decumbent; 3 = tall); IF = flowering intensity ( 0 = not flowering; 1 = small flowering; 2 = medium flowering; 3 = intense flowering).

Tabela 3 - Resumo das estimativas das distâncias genéticas, com base na distância de Mahalanobis entre 76 acessos de trevo-branco, para as nove características avaliadas

Table 3 - Summary of the genetic distances estimates, based on the Mahalanobis distance among the 76 white clover accessions for the nine evaluated characters

\begin{tabular}{lcc}
\hline $\begin{array}{l}\text { Distância genética } \\
\text { Genetic distance }\end{array}$ & $\begin{array}{c}\text { Estimativa } \\
\text { Estimate }\end{array}$ & $\begin{array}{c}\text { Acesso } \\
\text { Accession }\end{array}$ \\
\hline $\begin{array}{l}\text { Máxima } \\
\text { Maximum }\end{array}$ & 45,435812 & 1 e 10 \\
Mínima & 0,188262 & 58 e 68
\end{tabular}

Minimum

Soma das estimativas

23292,638871

Estimate sum

Soma de quadrados das estimativas 342723,682723

Estimate sum of squares

Média das estimativas $\quad 8,172856$

Estimate mean

A caracterização de cada um dos 12 grupos formados encontra-se na Tabela 5.

O grupo 3 foi o que reuniu os acessos com maior área foliar (média de 11,84 - com mínimo de 10,19 e máximo de $\left.13,16 \mathrm{~cm}^{2}\right)$ e estatura (17,08 - de 15,47 a 18,82 cm) e menor hábito de crescimento, ou seja, acessos prostrados; o grupo 7 foi formado pelos acessos com maior produção total de MS (63,77 - de 57,76 a 69,77 g de MS/planta), maior comprimento de estolão $(31,52 \mathrm{~cm})$ e de entrenós $(2,17 \mathrm{~cm})$, além de grande área foliar (média de $9,91 \mathrm{~cm}^{2}$ ). $\mathrm{O}$ acesso 10 foi o único integrante do grupo 10, o qual apresentou menor área foliar (média de $1,85 \mathrm{~cm}^{2}$ ), menor produção total de MS (aproximadamente 8,09 gMS/planta), menor estatura $(4,69 \mathrm{~cm})$ e menor diâmetro de estolão $(1,78 \mathrm{~cm})$.

A área foliar foi a característica que apresentou maior contribuição para a divergência entre os genótipos, sendo responsável por $23,62 \%$ da divergência (Tabela 6). A segunda característica de maior contribuição foi a estatura, seguida da intensidade de florescimento, da produção de MS, do hábito de crescimento, do comprimento de estolão, do comprimento de entrenós, do diâmetro de estolão e, por último, do número de nós por estolão. A área foliar, a estatura e a intensidade de florescimento juntas contribuíram com $62,92 \%$ da divergência.

A área foliar, neste trabalho, teve grande importância para a divergência dos acessos, como relatado por Caradus et al. (1989), que classificaram a coleção mundial composta por 109 cultivares de trevo-branco por meio da morfologia, 
Tabela 4 - Grupos de acessos estabelecidos pelo método de Tocher, com base na dissimilaridade genética expressa pela distância de Mahalanobis

Table 4 - Accessions groups formed by the Tocher method, based on the genetic dissimilarity expressed by the Mahalanobis distance

\begin{tabular}{ll}
$\begin{array}{l}\text { Grupo } \\
\text { Group }\end{array}$ & \multicolumn{1}{c}{$\begin{array}{c}\text { Acesso } \\
\text { Accession }\end{array}$} \\
\hline 1 & $6,8,11,13,19,26,28,29,37,40,51,53,56,58,59,61,68,69,70 \mathrm{e} 72$ \\
2 & $5,14,15,22,23,24,27,30,42,43,45,46,47,55,63,64,65,66,73,76 \mathrm{e} 77$ \\
3 & $1,3,9,25,49,50 \mathrm{e} 74$ \\
4 & $12,32,34,35,39,41,44,57,60 \mathrm{e} 71$ \\
5 & $18,21,31,54 \mathrm{e} 62$ \\
6 & $7,17,20 \mathrm{e} 67$ \\
7 & $2 \mathrm{e} 75$ \\
8 & $38 \mathrm{e} 48$ \\
9 & $4 \mathrm{e} 16$ \\
10 & 10 \\
11 & 78 \\
12 & 33 \\
\hline
\end{tabular}

Tabela 5 - Perfil dos grupos de acessos de trevo-branco formados por meio da análise de agrupamento pelo método de Tocher de nove características morfo-agronômicas (valores médios, mínimos e máximos de cada grupo para as nove variáveis)

Table 5 - Profile of white clover accessions groups formed by the Tocher method of grouping analysis of nine morpho-agronomic characters (minimum, maximum and average values within each group for the nine variables)

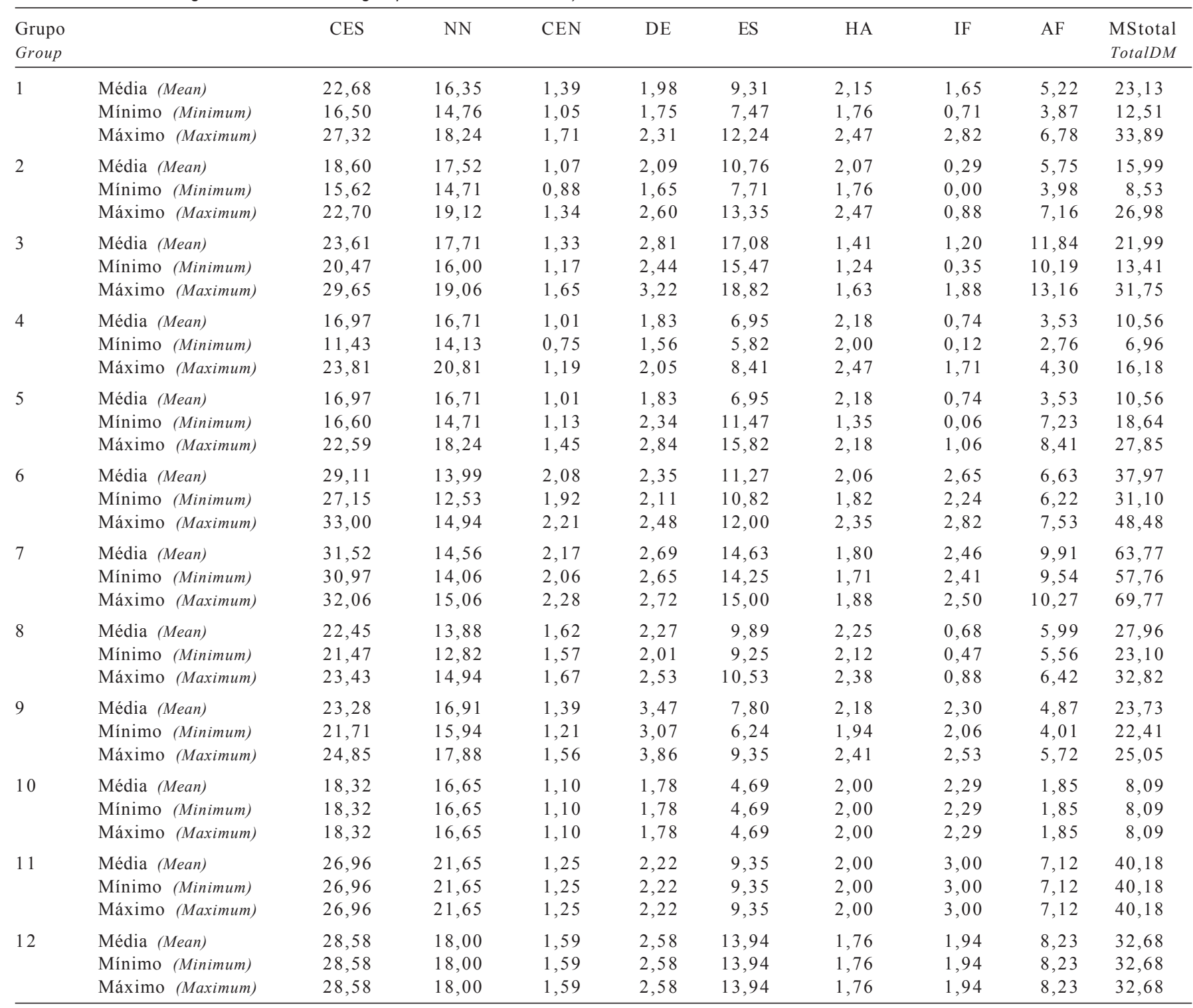


Tabela 6 - Contribuição relativa dos caracteres para divergência entre os acessos

Table 6 - Relative contribution of characteristics for the genetic divergence among the accessions

\begin{tabular}{lc}
\hline Variável & $\begin{array}{c}\text { Valor (\%) } \\
\text { Variable }\end{array}$ \\
\hline Área foliar (Leaf area) $\left(\mathrm{cm}^{2}\right)$ & 23,62 \\
Estatura (Height) (cm) & 20,37 \\
Intensidade de florescimento (Flowering intensity) & 18,93 \\
Produção total de matéria seca (Total dry matter yield) (g) & 14,72 \\
Hábito de crescimento (Growth habit) & 7,13 \\
Comprimento de estolão (Stolon length) (cm) & 5,15 \\
Comprimento de entrenós (Internode length) (cm) & 4,11 \\
Diâmetro de estolão (Stolon diameter) (mm) & 3,54 \\
Número de nós por estolão (Number of nodes per stolon) & 2,43 \\
\hline
\end{tabular}

do florescimento, da cianogênese e das marcas nas folhas. É importante ressaltar a pequena contribuição relativa do diâmetro de estolão e do comprimento de entrenós que outros autores (Carámbula, s.d.; Rosso \& Pagano, 2001) ressaltaram como importantes. Todavia, o número de nós por estolão foi a característica que menos contribuiu para a divergência dos acessos.

A partir dos resultados (Tabela 7), verifica-se alta correlação positiva entre a estatura e a área foliar $(\mathrm{r}=0,92)$, assim como entre o comprimento de estolão e o de entrenó $(\mathrm{r}=0,90)$, ambas altamente significativas, pois evidenciaram a importância biológica dessas características. Esses resultados indicaram que, quanto maior a área foliar, mais altas as plantas, provavelmente em razão do comprimento do pecíolo (não medido), pois plantas com maior área foliar possuem maior pecíolo e, conseqüentemente, maior estatura, corroborando os resultados obtidos por Carámbula (s.d.), Beinhart (1963) e Viecelli (2000). Além de servir para classificar o trevo-branco, a área foliar serve como parâmetro para selecionar tipos morfológicos mais persistentes em condições adversas de alta temperatura e baixa umidade (Carámbula, s.d.). Quanto à correlação entre comprimento de estolão e comprimento de entrenós, quanto maior o comprimento de estolão, mais longos foram os entrenós. Conforme Sanderson et al. (2003), a persistência do trevobranco nas pastagens deve-se principalmente ao crescimento do estolão, sendo necessário um manejo que mantenha um importante comprimento e massa de estolão para auxiliar na persistência e competitividade do trevo-branco.

De acordo com Gustine et al. (2002), plantas de trevobranco de folhas grandes apresentaram maiores pecíolos, maiores entrenós e estolões mais delgados e pobremente enraizados. Entretanto, Carámbula (s.d.) e Mather et al. (1995) afirmaram que os tipos de folhas grandes apresentam porte mais alto, estolões mais grossos e hábito mais ereto. Neste estudo, houve correlação positiva e altamente
Tabela 7 - Correlações lineares simples entre as variáveis comprimento de estolão (CES), número de nós/estolão (NN), comprimento de entrenós (CEN), diâmetro de estolão (DE), estatura (ES), área foliar/folha (AF) e produção total de matéria seca (MS total)

Table 7 - Simple linear correlations between the variables: stolon length (CES), number of nodes per stolon (NN), internode length $(C E N)$, stolon diameter (DE), plant height (ES), leaf area per leaf $(A F)$ and total dry matter yield (MS total)

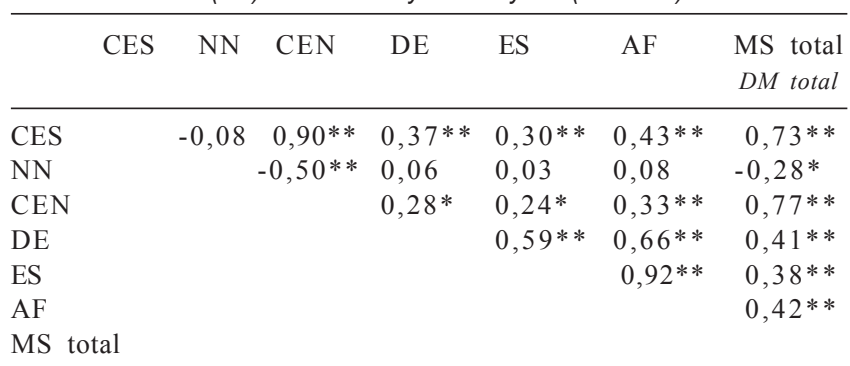

* Significativo a $5 \%$ de probabilidade pelo teste $t(P<0,05)$.

** Significativo a $1 \%$ de probabilidade pelo teste $t(P \leq 0,01)$.

* Significant at $5 \%$ by t test $(P<0.05)$.

** Significant at $1 \%$ by test $(P \leq 0.01)$.

significativa entre o diâmetro de estolão e duas dessas variáveis (estatura e área foliar) apresentando coeficientes de correlação de 0,59 e 0,66 , respectivamente, deixando evidente a associação do diâmetro de estolão a essas características.

Carámbula (s.d.) e Eisinger \& Paim (1994) verificaram que plantas com estolões mais longos geralmente apresentam menor rendimento de MS e, adicionalmente, Rosso \& Pagano (2001) citaram que populações de folhas grandes apresentaram maiores rendimentos de MS. Ambas as afirmativas puderam ser confirmadas neste trabalho, pois tanto as correlações entre produção total de MS e comprimento de estolão como entre produção total de MS e área foliar foram altas, positivas e altamente significativas $(0,73$ e 0,42 , respectivamente), evidenciando associação entre o comportamento dessas variáveis. Segundo Collins et al. (1997), o comprimento dos estolões, o tamanho das folhas e a produção de pecíolos são importantes indicadores da produção do trevo-branco quando submetido ao pastejo.

Eisinger \& Paim (1994) observaram que os clones com baixa produção de MS cresceram menos em altura, evidenciando correlação positiva entre produção de MS e estatura. Essa relação apresentou coeficiente de correlação positivo e altamente significativo neste trabalho $(0,38)$, assim como a relação produção total de MS x comprimento de entrenós $(0,77)$.

\section{Conclusões}

Há ampla variabilidade genética na coleção nuclear de trevo-branco quanto às características morfológicas, atestada pela distância genética. 
Considerando-se a estimativa da distância de Mahalanobis, os acessos 1 (PI 195534) e 10 (PI 419325) foram os que apresentaram a maior distância $(45,4)$ e os acessos 58 (PI 180491) e 68 (PI 197830), a menor $(0,19)$.

Pelo método de Singh, com base na distância de Mahalanobis, a área foliar, a estatura e intensidade de florescimento e a produção total de matéria seca foram os principais aspectos discriminatórios dos acessos.

Houve alta correlação positiva e altamente significativa entre a estatura e a área foliar, assim como entre o comprimento de estolão e o comprimento de entrenós.

\section{Agradecimento}

Ao CNPq, pela bolsa de estudos concedida; ao Departamento de Agricultura dos Estados Unidos, pelo fornecimento das sementes; e aos bolsistas e voluntários do Departamento de Plantas Forrageiras e Agrometeorologia da Faculdade de Agronomia da Universidade Federal do Rio Grande do Sul, pela grande ajuda nas avaliações.

\section{Literatura Citada}

ALVES, M.I.F.; MACHADO, A.A.; ZONTA, E.P. Tópicos especiais de estatística experimental utilizando o SANEST (Sistema de Análise Estatística para Microcomputadores). In: SIMPÓSIO DE ESTATÍSTICA APLICADA À EXPERIMENTAÇÃO AGRONÔMICA, 5.; REUNIÃO ANUAL DA SOCIEDADE INTERNACIONAL DE BIOMETRIA, 38., 1993, Porto Alegre. Anais... Porto Alegre: Universidade Federal do Rio Grande do Sul, 1993. p.1-110.

ARANA, S.; PIÑEIRO, G.; GARCIA, J. et al. Riego y manejo en la productividad de pasturas con trébol blanco. In: JORNADA DE TREBOL BLANCO, 1., 2000, Estanzuela. Anais... Estanzuela: Instituto Nacional de Investigación Agropecuaria, 2000. p.5-12. (Serie Actividades de Difusión, 241)

BEINHART, G. Effects of environment on meristematic development, leaf area, and growth of white clover. Crop Science, v.3, n.1, p.209-214, 1963.

CARADUS, J.R.; MACKAY, A.C.; WOODFIELD, D.R. et al. Classification of a world collection of white clover cultivars. Euphytica, v.42, n.1-2, p.183-196, 1989.

CARÁmBUlA, M. Produccion y manejo de pasturas sembradas. Montevideo: Hemisferio Sur, [s.d.]. 464p.

COLLINS, R.P.; ABBERTONI, M.T.; MICHAELSON-YEATES, T.P.T. et al. Response to divergent selection for stolon characters in white clover (Trifolium repens L.). Journal of Agricultural Science, v.129, n.3, p.279-285, 1997.

CRUZ, C.D. Programa Genes - versão Windows: aplicativo computacional em genética e estatística. Viçosa, MG: Universidade Federal de Viçosa, 2001. 648p.

EISINGER, S.M.; PAIM, N.R. Avaliação de clones de trevo branco sob diferentes níveis de calcário e fósforo do solo. I. Taxas de crescimento e produção de forragem. Revista da Sociedade Brasileira de Zootecnia, v.23, n.3, p.383-393, 1994.

FRAME, J.; CHARLTON, J.F.L.; LAIDLAW, A.S. Temperate forage legumes. Wallingford: CAB International, 1997. 327p.

GARCÍA, J.A. Variedades de trebol blanco. Montevideo: Instituto Nacional de Investigación Agropecuaria, 1995. 12p. (Série Técnica, 70)

GARCÍA, J.A. Mejoramiento de trebol blanco. In: JORNADA DE TREBOl BlAnCO, 1., 2000, Estanzuela. Anais...
Estanzuela: Instituto Nacional de Investigación Agropecuaria, 2000. p.1-4 (Serie Actividades de Difusión, 241)

GIBSON, P.B.; HOLLOWELL, E.A. White clover. In: Agriculture handbook. Washington, D.C.: United States Department of Agriculture, 1966. 33p (Agriculture Handbook, 314)

GUSTINE, D.L.; VOIGT, P.W.; BRUMMER, E.C. et al. Genetic variation of RAPD markers for north american white clover collections and cultivars. Crop Science, v.42, n.2, p.343-347, 2002.

HELGADÓTTIR, A.; DALMANNSDÓTTIR, S.; COLLINS, R.P. Adaptational changes in white clover population selected under marginal conditions. Annals of Botany, v. 88 , n.4, p.771-780, 2001 .

INTERNATIONAL BOARD FOR PLANT GENETIC RESOURCES - IBPGR. Descriptors for white clover (Trifolium repens L.). Rome: 1992. 52p.

JAHUFER, M.Z.Z.; COOPER, M.; AYRES, J.F. et al. Identification of research to improve the efficiency of breeding strategies for white clover in Australia - a review. Australian Journal of Agricultural Research, v.53, n.3, p.239-257, 2002.

LÜSCHER, A.; ATÄHELI, B.; BRAUN, R. et al. Leaf area, competition with grass, and clover cultivar: key factors to successful overwintering and fast regrowth of white clover (Trifolium repens L.) in spring. Annals of Botany, v.88, n.4, p.725-735, 2001.

MATHER, R.D.J.; MELHUISH, D.T; HERLIHY, M. Trends in the global marketing of white clover cultivars. In: WOODFIELD, D.R. (Ed.) White clover: New Zealand's competitive edge. New Zealand: Lincoln University, 1995. p.7-14.

NABINGER, C. Técnicas de melhoramento de pastagens naturais no Rio Grande do Sul. In: SEMINÁRIO SOBRE PASTAGENS: "DE QUE PASTAGENS NECESSITAMOS", 1980, Porto Alegre. Anais... Porto Alegre: Federação da Agricultura do Estado do Rio Grande do Sul, 1980. p.28-58.

PAIM, N.R. Manejo de leguminosas de clima temperado. In: SIMPÓSIO SOBRE MANEJO DE PASTAGEM, 9., 1988, Piracicaba. Anais... Piracicaba: Fundação de Estudos Agrários Luiz de Queiroz, 1988. p.341-358.

PAIM, N.R. White clover to improve natural grasslands in southern Brazil. In: INTERNATIONAL GRASSLAND CONGRESS, 17. 1993, Palmerston North. Proceedings... Palmerston North: 1993. p.455-456.

PAIM, N.R.; RIBOLDI, J. Duas novas cultivares de trevo branco comparadas com outras disponíveis no Rio Grande do Sul, em associação com gramíneas. Pesquisa Agropecuária Brasileira, v.29, n.1, p.43-53, 1994.

ROSSO, B.S.; PAGANO, E.M. Collection e characterization of populations of white clover (Trifolium repens L.) in Argentina. Genetic Resources and Crop Evolution, v.48, n.5, p.513-517, 2001

SANDERSON, M.A.; BYERS, R.A.; SKINNER, R.H. et al. Growth and complexity of white clover stolons in response to biotic and abiotic stress. Crop Science, v.43, n.6, p.2197-2205, 2003.

SEKER, H.; ROWE, D.E.; BRINK, G.E. White clover morphology changes with stress treatments. Crop Science, v.43, n.6, p.2218-2225, 2003.

STRECK, E.V.; KÄMPF, N.; DALMOLIN, R.S.D. et al. Solos do Rio Grande do Sul. Porto Alegre: EMATER/RS; UFRGS, 2002. 128p.

THOMAS, R.G. Growth of the white clover plant in relation to seed production. In: LANCASHIRE, J.A. (Ed.) Herbage seed production. New Zealand: Editorial Service Limited, 1980. p.56-63.

VIECELLI, L.C. Melhoramento genético de trevo branco (Trifolium repens L.) visando persistência e produção. Porto Alegre: Universidade Federal do Rio Grande do Sul, 2000. 135p. Dissertação (Mestrado em Zootecnia) - Universidade Federal do Rio Grande do Sul, 2000.

ZOHARY, M.; HELLER, D. The genus Trifolium. Jerusalem: The Israel Academy of Sciences and Humanities, 1984. 606p.

Recebido: 25/10/04 Aprovado: 10/04/06 